\title{
A Review of the Placenta and Trophoblast Induced Pluripotent Stem Cells in Autism Spectrum Disorder Research
}

\section{Sona Jasani ${ }^{1^{*}}$, Grace Tartaglia ${ }^{2}$, Percy Luk Yeung ${ }^{3}$ and Chi-Wei Lu $^{3}$}

${ }^{1}$ Department of Obstetrics, Gynecology and Reproductive Sciences, Rutgers Robert Wood Johnson Medical School, 125 Paterson Street, New Brunswick, New Jersey, USA ${ }^{2}$ Graduate School of Biomedical Sciences, Rutgers University, 675 Hoes Lane, Piscataway, NJ, USA

${ }^{3}$ Child Health Institute of New Jersey, Department of Obstetrics, Gynecology and Reproductive Sciences, Rutgers Robert Wood Johnson Medical School, 125 Paterson Street, New Brunswick, New Jersey, USA

\begin{abstract}
Autism spectrum disorder (ASD) imparts a tremendous health burden with psychological, social, and economic implications. The biology of ASD is complex involving genetic, molecular, hormonal and immunologic factors however the convergence point of these various factors has not been identified as of yet. Limited evidence exists to suggest that the placenta may play such a governing role in ASD manifestation. The placenta is a neuroendocrine modulator by participating in the fetal hypothalamic pituitary gonadal (HPG) axis and also regulates the intrauterine environment mitigating fetal exposure to damaging factors to modulate the fetal stress response. Placental dysfunction has been associated with developmental abnormality and neuropsychiatric pathology adding to the biologic plausibility of the governing role the placenta may play in ASD development. By using current technology like induced pluripotent stem cells (iPSCs), a practical model system can be created to study ASD providing an alternative method to further research the placenta in ASD development
\end{abstract}

Keywords: Placenta; Trophoblast; Autism spectrum disorder; Induced pluripotent stem cell; Neuroendocrine regulator; Maternal immune activation

\section{Introduction}

Autism spectrum disorder (ASD) poses a great health burden and a tremendous effort towards researching the etiology has been performed. Though a great body of research has identified candidate genes, gene networks, and possible molecular pathways, the underlying regulation of these steps is currently unknown. Broadening ASD research to include environmental exposures and perinatal factors has not identified a convergence point of these various players. Neurobiological findings suggest that ASD pathophysiology may originate during fetal development [1-9]. Given this data, a plausible convergence point appears to be the placenta, which is known to regulate proper fetal development in utero. The placenta could therefore be thought of as the final common pathway in the development of ASD merging pertinent genetic, structural and environmental factors that impact fetal brain development. Targeting the placenta and trophoblast in understanding the complex biology of ASD may therefore be a more effective strategy to guide basic, translational and clinical science research.

One challenge that exists in furthering ASD research is the lack of a standard model system to study the etiology of the disorder. Most research about autism is based on retrospective studies, biological samples taken from autistic adults, or post-mortem brain autopsies. While useful in identifying biomarkers in autistic individuals, there is difficulty in proving causation rather than just correlation. These methods have proven to have limitations decreasing their efficacy in developing a comprehensive ASD model. Induced pluripotent stem cell (iPSC) technology can advance current ASD research by providing a means of circumventing the limitations associated with traditional research paradigms. Recreation of placental tissues from individuals diagnosed with ASD can be achieved by converting cryopreserved peripheral blood cells into iPSCs [10] and then inducing differentiation toward hormone secreting trophoblast cell types [11]. While conditions to induce iPSCs toward trophoblast development remains to be refined, some of the different trophoblast and neural cell features of autism patients can be reflected in such experimental systems [12]. This technology provides a solution to tissue availability and prolonged placental tissue cryopreservation. Use of iPSCs may identify the cellular and genetic pathways related to ASD and can elucidate the epigenetic and synergistic effects of the environment and stress on such pathways within the placenta. A tissue culture model is capable of measuring cellular response to different stimuli including pro-inflammatory cytokines, infectious agents, pesticides and oxidative stresses, all of which can be administered in the trophoblast culture system. The iPSC-trophoblast model is therefore ideal for investigation by creating placental precursor stem cells to examine the trophoblast and placental role in integrating genetic, hormonal, environmental and perinatal contributors to autism.

This article summaries the limited existing data supporting the placental convergence hypothesis. We review the biology and pathophysiology of the placenta with respect to neuropsychiatric outcomes highlighting trophoblast development and function with respect to neuromodulation and brain morphology, demonstrating the placental role in neurodevelopmental environment regulation and explaining differential placental gene expression involved with neuromodulation. We further review existing data discussing the resultant pathology that occurs from placental dysregulation in other organ systems to argue the idea of biologic plausibility of placental

*Corresponding author: Sona Jasani, Clinical Instructor and Academic Faculty Scholar, Robert Wood Johnson Medical School, Department of Obstetrics, Gynecology and Reproductive Services, 125 Paterson St., New Brunswick, NJ 08901, USA, Tel: 732-235-6623; Fax: 732-235-7349; E-mail: sjasani@rwjms.rutgers.edu; sona.jasani@gmail.com

Received February 12, 2018; Accepted February 27, 2018; Published February 28,2018

Citation: Jasani S, Tartaglia G, Yeung PL, Lu CW (2018) A Review of the Placenta and Trophoblast Induced Pluripotent Stem Cells in Autism Spectrum Disorder Research. J Stem Cell Res Ther 8: 413. doi: 10.4172/2157-7633.1000413

Copyright: (C) 2018 Jasani S, et al. This is an open-access article distributed under the terms of the Creative Commons Attribution License, which permits unrestricted use, distribution, and reproduction in any medium, provided the original author and source are credited. 
function in ASD formation. We also briefly review the clinically relevant data regarding the placental role in fetal stress response programming and maternal immune activation. Finally we review the study of iPSCs in ASD research and suggest that iPSCs can also help establish causational data to support the role of the placenta in ASD emergence. If iPSCs are also used to help examine differential gene expression the model system could contribute to efforts for potential reversal of the ASD phenotype.

\section{The placenta governs neural development through hormone secretion}

Trophoblasts are the precursors of the placenta and play a regulatory role in fetal neural brain development through a highly coordinated sequence of developmental events. Just 8 days after implantation, the trophoblast cells form the syncytiotrophoblast, the outer multinucleated layer, and the cytotrophoblast, the inner mononuclear layer [13]. The syncytiotrophoblast secretes the hormone human chorionic gonadotropin (HCG) which among its various functions is thought to play a role in neurodevelopment. HCG belongs to the same growth factor family as nerve growth factor and animal studies have demonstrated increased neurite processes and decreased apoptosis in in vitro studies of fetal rat brains cultured with HCG. This hormone may also function in behavior regulation as areas within the brain related to behavior including the hippocampus and hypothalamus express high levels of HCG receptors [14]. The syncytiotrophoblast creates an interconnecting network of vascular channels 12 days after implantation so that by day 17 , placental circulation is established [15]. Shortly after the establishment of this blueprint of fetal circulation, fetal neurodevelopment begins to take center stage. At 3 weeks of gestation, neural tube formation begins as regulated by modulatory effects from the notochord. In vitro studies of early human embryogenesis demonstrates that HCG secreted by the trophoblast influences embryoblast development and growth as well as induces progesterone synthesis, an obligatory role in neural precursor cell and neural tube formation through autocrine and paracrine methods [16]. Furthermore, in vitro studies of messenger RNA (mRNA) expression demonstrate that human placental cells produce follistatin, which along with inhibin, exerts an inhibitory effect on placental HCG secretion [17]. In vitro and animal studies provide evidence that neural development is influenced by trophoblast cells which are able to create vascular networks. This vasculature composes the proper regulatory hormonal milieu influencing nervous system and fetal brain development which if dysregulated may result in clinical neuropathology [18]. Use of iPSCs may provide a promising tool to advance research in this area. Emphasis on creating induced trophoblast cells as opposed to neural stem cells may offer a unique insight into the neuromodulatory factors occurring in utero at early gestational ages. Trophoblast differentiated stem cells could be used to measure differences in secretion of HCG, follistatin and progesterone between autistic and non-autistic individuals.

\section{The placenta influences neuronal function and brain morphology}

Differences in brain functioning including multiregional dysregulation of neurogenesis, migration, maturation, neuronal hyperreactivity and reduced neural synchronization have been identified in individuals with ASD $[12,19]$. Evidence suggests that the placenta might be involved in some of these functions through epigenetic mechanisms [20-22]. The establishment of proper neuronal functioning as mediated through migration, organization and myelination begins in fetal life around 12-20 weeks gestation with some processes continuing into postnatal life [23]. Migrating neurons will await connections from afferent neurons in the thalamus, basal forebrain and brainstem in order to undertake the necessary developmental steps [2] and as the fetal brain undergoes these dynamic processes, the placenta provides both transport of necessary metabolic nutrients and neuroendocrine functions necessary to support fetal brain development [20]. Evidence also exists suggesting the placenta may influence neuroanatomy. Neuronal proliferation begins around 12-16 weeks of gestation [23] and may be mediated early on by placental secreted factors including HCG and follistatin [14]. It is likely that improper secretion of these hormones by the placental trophoblast may result in too many or too few neural connections. Macrocephaly is a noted clinical feature of children with autism and postmortem studies of ASD individuals have revealed an excess amount of neurons in the prefrontal cortex. MRI studies in individuals at risk for psychiatric and cognitive disorders have demonstrated volume reduction in areas of the brain associated with these nervous system processes [3]. Animal models have demonstrated that the onset and duration of placental insult produces varied neuropathological outcomes and similar morphologic and functional changes seen in human neuropathology [2]. As the nervous system undergoes dynamic change throughout gestation and into postnatal life with the rate of neurogenesis equaling approximately 40,000 synapses per second, this process is likely subjected to modulatory factors both essential and detrimental. A trophoblast-differentiated model would allow for a systematic examination of the specific metabolic nutrients and neuroendocrine factors necessary for neural functioning and fetal brain anatomy. Use of iPSCs may aid to clarify the exact pathways responsible for these associations advancing the knowledge provided by current animal and in vitro models.

\section{The placenta actively regulates environmental determinants of nervous system physiology}

The placenta functions as a transport organ to provide necessary nutrients to the developing fetus. During prenatal development, the placenta serves to maintain homeostasis and control environmental exposures [24,25]. Environmental triggers found to increase the risks of neurodevelopmental disorders during pregnancy include nutrition, stress, infection, and inflammation. The possible insults that can affect the developing fetus are diverse; however the placenta determines whether these insults can be transmitted to the developing fetus [26,27] The placenta plays a role maintaining the delicate balance of nutrients such as metals which are known to influence fetal brain development. Metallothionein-1 is found within the syncytiotrophoblast and is known to bind heavy metals [28]. Furthermore, human studies have shown differing concentrations of metals by gestational age, suggesting that the placenta may actively regulate the concentrations of certain metals for various neurodevelopmental processes and pathways [28]. Disruption of the delicate balance of metal concentration may lead to neurobehavioral pathology. Lower whole body zinc levels and zinc to copper ratios have been seen in children with ASD [29]. Preconception zinc deficiency has caused aberrant neural tube development in mice [30] and it appears that supplementation of metals in individuals with micronutrient deficiency may modulate placental vascular function in humans [31]. Furthermore, both zinc and copper are regarded as neurotransmitters with high concentrations in the hippocampus. Disruptions in the balance of these metals have been associated in behavior disorders [32]. The enzymes involved in metal processing have been associated with certain types of neuropathology and the placenta is thought to be a key regulator in these metabolic pathways. Copper is oxidized by the protein ceruloplasmin (CP), an iron transporter, and is studied in the etiology of autism, schizophrenia, 
and obsessive-compulsive disorder. $\mathrm{CP}$ is an acute phase reactant that is regulated by cytokines in response to hypoxia resulting from infection or inflammation. The placenta also has receptors for $\mathrm{CP}$ to deliver copper to the fetus [33]. High levels of CP protein are present in placental tissue, specifically in cases of preeclampsia [34]. When comparing autistic individuals to their non-autistic siblings, lower $\mathrm{CP}$ levels were detected in autistic children who lost "previously acquired language skills" as compared to those individuals who did not [35]. This suggests that low CP levels might contribute to the clinical presentation of neurodegeneration seen in autistic individuals. The underlying mechanism of this observation is thought to be due to elevated iron concentration that occurs with decreased CP leading to cerebral damage [35]. The data involving metals and brain development both basic science and clinical observational studies seems to support the connection between placental function and neuropathology.

\section{Differential gene expression within the placenta influences neuroendocrine regulation of brain development}

Differential gene expression, especially seen from gender differences, has been theorized to explain features of ASD [36-38]. Interestingly, gender differences in gene expression within the human placenta have been identified [39-41] and are associated with clinical outcomes such as differential fetal growth [42] and stress response [43]. Given the genetic heterogeneity of ASD and the numerous implicated genes [44-47] the placenta appears to be a likely a convergence point of differential gene expression. Many of the implicated genes are known to affect components of the hypothalamic pituitary gonadal (HPG) axis, a known neuroendocrine regulator of brain development, of which the placenta is a major component. Alteration in the HPG axis has demonstrated varied neurologic effects primarily through follicle stimulating hormone (FSH). A promising cluster of candidate genes labeled as the Root 66 genes has revealed a non-random association with ASD and the HPG axis. When we cross-referenced these 66 genes, we determined that 50 of them have gene or protein expression within placental trophoblasts or decidua [48]. Furthermore, research involving the use of iPSCs to re-create an "autistic cell" has suggested that ASD likely arises from a common developmental origin [36]. Given that the HPG axis is highly conserved among species, it is very plausible that the conserved pathways of neuronal and endocrine development are regulated by the placenta, which has demonstrated to affect both these aspects.

\section{Placental dysfunction leads to developmental abnormality}

The human placenta serves as a regulator of fetal programing in other organ systems, which when altered, results in pathology [49]. Various human and animal studies suggest that the development of many chronic diseases including heart disease, obesity, hypertension and type 2 diabetes originate in prenatal life [50-59]. The cardiovascular health after maternal placental syndromes (CHAMPS) study demonstrated a doubling in the risk of premature cardiovascular disease in women without a previous history of cardiac disease who had a maternal placental syndrome during pregnancy [51]. Furthermore, expression of placental genes has been shown to impact fetal cardiac function and anatomy. One such gene, HOXA13, which is expressed in placental and not cardiac tissue, is involved with cardiovascular development. Knockout HOXA13 mice results in abnormal placental endothelium and is associated with a reduction in ventricular wall thickness leading to embryonic death [50]. There is also evidence to support the idea that vulnerability to disease is "programmed" in fetal life with a growing body of evidence linking intrauterine environment, neurodevelopment and subsequent neuropsychological outcomes [60]. An iPSC trophoblast model would provide vital real-time data regarding the neuromodulatory role that the placenta plays in both ASD affected and unaffected individuals.

The placenta impacts neuronal cellular structure and function [3]; additionally, clinically relevant physiologic associations between the placenta and fetal brain development such as brain sparing have also been seen. This phenomenon occurs in human developmental pathophysiology when the fetus alters hemocirculation to preserve oxygen and nutrient supply to the brain in the setting of placental insufficiency. Brain sparing occurs regionally and in a hierarchical order with an initial attempt to preserve higher cognitive function areas first, though prolonged placental insult will result in shifting towards preserving survival areas of the brain. This physiologic phenomenon is thought to be a protective mechanism; however, prolonged brain sparing may lead to negative consequences persisting postnatally [61] Sheep models of chronic placental insufficiency in the second half of gestation demonstrate features of brain sparing and Guinea pig models of chronic placental insufficiency have resulted in schizophrenia-like features comparable to those found in humans [2]. Whether brain sparing from prolonged placental insult is causational in resultant neurocognitive and neuropsychiatric pathology remains unknown, placental insult appears connected to proper neurodevelopment and brain function. Genetic predisposition may influence the likelihood of placental dysfunction resulting in clinical pathology however, further studies are needed. The current limited data seems to support a tight connection between the brain and the placenta during prenatal development [62].

Fetal stress response is prenatally programed by the placenta and may result in neuropsychiatric pathology when disrupted

Mammalian systemic stress responses are controlled by the hypothalamic pituitary adrenocortex (HPA) axis, which exerts its regulatory effects through the concentrations of corticotropin-releasing hormone ( $\mathrm{CRH}$ ) from the hypothalamus, adrenocorticotropic hormone (ACTH) from the pituitary, and cortisol from the adrenal cortex. During pregnancy, the placenta plays a pivotal role in balancing the maternal HPA activities thereby modulating the fetal stress response. The placenta secretes $\mathrm{CRH}$ and expresses $11 \beta$-Hydroxysteroid dehydrogenase (11 $\beta$-HSD), which regulates how maternal glucocorticoids enter the fetal bloodstream and cortisol's effects $[63,64]$. In addition, the placenta has been shown to produce and secrete serotonin which accumulates in the fetal forebrain at mid-gestation [65] connecting the stress response pathways to direct neurologic effects within the developing fetus. These placental mechanisms not only control fetal exposure to maternal stress, but also provide feedback regulation for the maternal HPA axis to attenuate stress level as pregnancy proceeds [66-68]. Genetic variations leading to differential expression of glucocorticoid and $\mathrm{CRH}$ receptors associated with depression and stress disorders may impact the maternal HPA axis and fetal stress response [69-71]. Furthermore, sexual dimorphism in the execution of the HPA axis has already been observed in neurodevelopmental abnormalities. Studies in patients with congenital adrenal hyperplasia, a condition of abnormal cortisol metabolism, have shown increased autistic like behaviors in affected females but not in males when compared to controls $[37,72]$. Hormone activity in the HPA axis can be detected as early as 8-12 weeks of gestation and is regulated by the placenta through feedback loops involving cortisol, a factor for proper maturation of organ systems including the central nervous system [73].

Placental modulation of the stress pathway can also be influenced 
by many other maternal factors, one being nutritional status. Murine studies demonstrate the importance of the placenta in protecting the fetal brain [74]. In a dietary deprivation model, changes in gene expression favoring the catabolic pathways were only observed in the placenta without altering the fetal hypothalamus. On the contrary, elevated expression of transporter proteins was observed in the fetal hypothalamus but not in the placenta [75]. This may explain the dire outcomes of human development, including metabolic disease and psychiatric disorders during famine [76]. Maternal diet has been shown to influence placental glucocorticoid metabolism which can predispose offspring to hypertension [77,78], and is also known to reduce placental 11 $\beta$-HSD expression [79]. Changes in maternal cortisol level or in the placental HPA pathway have not only been linked to adverse birth outcomes, but also in neurodevelopmental outcomes including cognitive and behavioral changes, emotional reactivity and motor dysfunction [80-84].

\section{Maternal Immune activation: linking maternal stress to the development of ASD}

In addition to modulating stress response and allocating needed resources to the developing fetus, the placenta also protects the fetus from harmful exposures, especially inflammation. The maternal immune activation (MIA) model is useful in ASD research. The effects of MIA can potentially be mediated by inflammatory cytokines interleukins 1 and 6 (IL-1 and IL-6); maternal IL-6 is affiliated with limiting the signaling of cytokines through the placenta via gene expression (SOCS3). If an infection occurs during a certain time frame, the intensity of MIA can lead to fetal brain damage. In response to an infection, the mother's immune system normally will send out leukemia inhibitory factor (LIF) through the placenta and activate the LIF signaling pathway within the fetus. This "maternal-fetal signal relay" stimulates fetal neurogenesis of the cerebrum, as demonstrated in rat models [85]. A severe MIA reaction causes an increase in leukocytes and IL-6 production in rat models [86] and a decrease in fetal LIF, leading to stunted neurodevelopment. The cerebrum is subsequently damaged due to the lack of LIF in the fetal system and the high levels of IL-6 result in elevated SOCS3 expression which inhibits any further neurogenesis [85]. Placental trophoblast IL-6R $\alpha$ knockouts had decreased placental and fetal brain inflammation resulting in less irregular behaviors in mice offspring [87]. Similarly, placental and neurodevelopmental damage induced by lipopolysaccharide (LPS) mediated inflammation was shown to be alleviated by an IL-1 receptor antagonist [88].

Given that fetal susceptibility to MIA is observed during midgestation, it would be most informative to analyze biochemical changes in trophoblast-differentiated stem cells following activation of the immune system. The MIA model remains to be the most reproducible with phenotypes closely mimicking human ASD in mouse models of autism-like behavior disorders. Monogenic models often have incomplete penetrance making it difficult to link placental dysfunction with the autism phenotype. Changes in gene expression of the fetal brain have been observed in MIA models $[89,90]$ and these models should be used to analyze immediate placental gene expression responses to MIA. Long-term effects of MIA can subsequently be identified through genome wide analysis of epigenetic changes by identifying changes in DNA methylation patterns.

\section{Molecular and genetic differences should be examined in the placenta}

Gene expression analyses of other tissues reveal key changes in pregnancies complicated by ASD including natural killer cells, tissues of the prefrontal cortex, lymphocytes within peripheral blood and other tissues [91-94]. Examination of differences in baseline gene expression or after a stress challenge may identify or better clarify diagnostic and therapeutic targets for clinical use. Prolonged preservation of viable trophoblast tissue is labor intensive and costly. Stem cells from individuals with autism offer an alternative source of cells. A recent study used neuron-differentiated iPSCs from ASD affected persons with deletion or duplication of the $16 \mathrm{p} 11.2$ region to analyze the biological mechanisms underlying the macrocephaly and microcephaly phenotypes. This region is associated with a copy-number variant mutation linked to certain neurological disorders. This use of iPSC technology was able to demonstrate that reduced synaptic density, which likely would result in larger scale neuroanatomical changes within the brain as a whole, were a result of mutations in the $16 \mathrm{p} 11.2$ region [95]. Similarly, iPSC use may also elucidate the relationship of pathologic manifestations associated with ASD, such as trophoblast inclusions [96,97]. Stem cells can be induced into trophoblast cells, examined during various stages of development when exposed to differing environmental exposures or genetic/epigenetic changes and examined for the presence or absence of trophoblast inclusions. The iPSC model appears to allow for more efficient and effective methods to examine the ASD phenotype from genetic, epigenetic and molecular differences in the placenta and trophoblast which since now has been limited.

\section{Induced pluripotent stem cells as a model system}

Induced pluripotent stem cells are becoming more utilized in research for neurological disorders and are gaining more attention in ASD research and treatment. Studying neuron-differentiated iPSCs from patients has contributed to our limited knowledge of ASD pathogenesis and has facilitated drug screening platforms for therapeutics [98]. Previous to iPSC technology, there was a dearth of sufficient human samples of neurons to study these neurological disorders. With iPSCs, researchers can now analyze the mechanisms involved in neuronal cellular development from initial stage to an adult stem cell that may result in neuropsychiatric disorder manifestation [99]. A neuron-differentiated iPSC model system has revealed insights into the role dysfunctional glial cells play in ASD pathophysiology in addition to providing a means to test potential therapeutics [100] Currently the data examining iPSC technology in the placental trophoblast is limited and even more limited when examining this technology in ASD patients [11-12]. As the placenta plays a major role in fetal development, especially neural development, iPSC technology should not only be examined in neuronal cells but also in placental cells. By discussing the limited data supporting the role of the placenta in ASD and the even more limited research done about iPSC modeling for the connection between the placenta and ASD manifestation, we hope to spark more conversation and action into using this model system.

Of course, despite the usefulness of iPSCs, there are limitations. With iPSCs, there have been noted differences in the transcriptome, proteins, and the epigenome compared to embryonic stem cells. These differences could be due to the reprogramming process iPSCs undergo, which could also affect how efficiently the cells differentiate [12,101103]. Despite these identified limitations, iPSC technology does appear to be an effective tool to advance our comprehension of ASD. As with any model, understanding the limitations posed by the iPSC system will be vital to draw meaningful conclusions from future research endeavors (Figures 1 and 2, Table 1). 
Citation: Jasani S, Tartaglia G, Yeung PL, Lu CW (2018) A Review of the Placenta and Trophoblast Induced Pluripotent Stem Cells in Autism Spectrum Disorder Research. J Stem Cell Res Ther 8: 413. doi: 10.4172/2157-7633.1000413

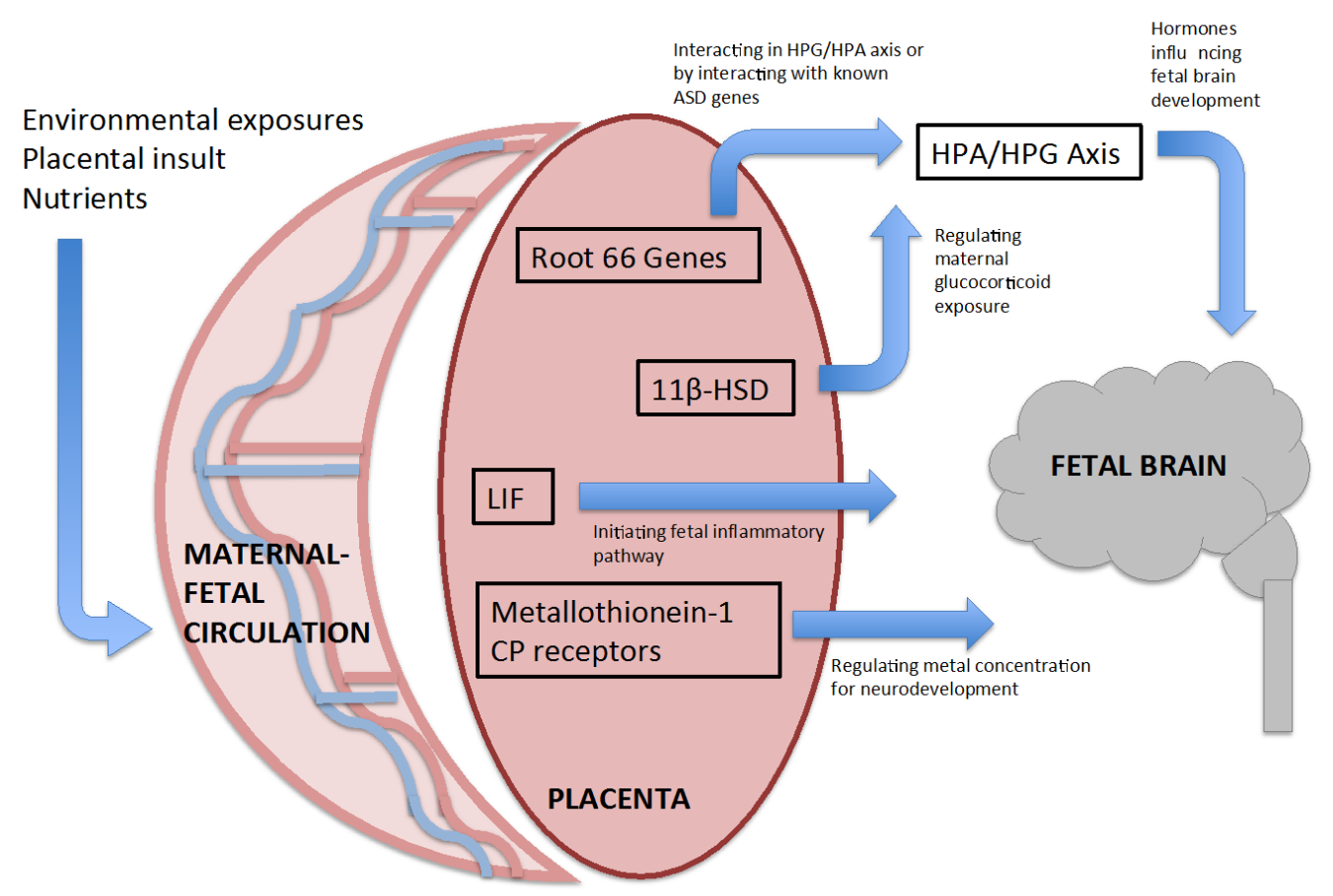

Figure 1: The placenta appears to function in fetal brain development through various proposed pathways including its participation in the HPA/HPG axis and as a regulator of insults and essential nutrients to provide a suitable environment for proper fetal brain development. Pathology including neuropsychiatric outcomes like ASD may result when placental dysfunction occurs.

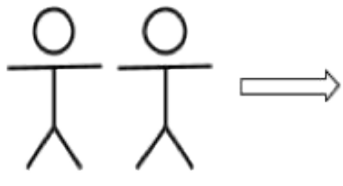

Autistic Patients

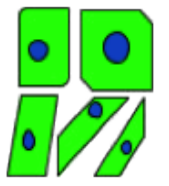

Fibroblasts

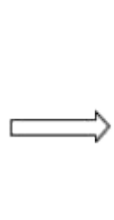

iPSCs

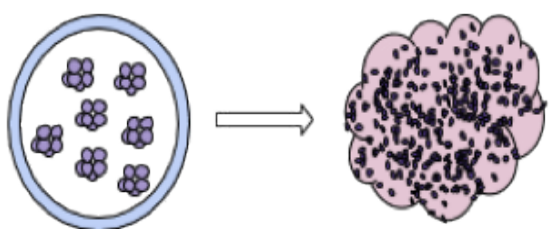

Trophoblast

Determine significant regulators of both fetal neuronal functioning and fetal brain morphology

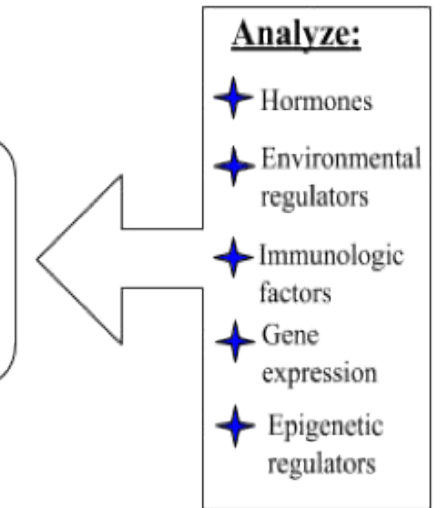

Figure 2: Utilizing iPSC technology, a model system can be constructed to understand trophoblast function in fetal brain development. Fibroblasts from autistic patients are induced into trophoblast cells. These induced cells can be used to measure hormone secretion, gene expression and epigenetics, immunologic factors and environmental exposures. These factors can be compared to non-autistic trophoblast controls to identify significant influencers in ASD pathophysiology. 
Citation: Jasani S, Tartaglia G, Yeung PL, Lu CW (2018) A Review of the Placenta and Trophoblast Induced Pluripotent Stem Cells in Autism Spectrum Disorder Research. J Stem Cell Res Ther 8: 413. doi: 10.4172/2157-7633.1000413

Page 6 of 11

\begin{tabular}{|c|c|c|c|c|c|}
\hline \multicolumn{6}{|c|}{50 of the Root 66 Genes Detected in Placenta } \\
\hline Class & Gene & Detection & Class & Gene & Detection \\
\hline \multirow{2}{*}{ Known to be Associated with Autism } & TCF4 & Low & \multirow{7}{*}{ Interact with ASD candidate genes } & SIRPA & Medium \\
\hline & UPF2 & Low & & SVIL & Medium \\
\hline \multirow{23}{*}{ Interact with ASD candidate gene } & ACSL4 & Medium & & TDP2 & Low \\
\hline & ASAH1 & Low & & TIMP2 & Medium \\
\hline & BAX & High & & TXN & Low \\
\hline & BCL6 & Low & & UBE2D3 & Medium \\
\hline & CAPZ A2 & Medium & & ZNF644 & Low \\
\hline & CNOT4 & High & \multirow{18}{*}{$\begin{array}{l}\text { Related to genes associated with } \\
\text { neurological conditions }\end{array}$} & AGTPBP1 & Medium \\
\hline & COL4ABP & Medium & & ARID4B & Low \\
\hline & CSF2RA & Low & & CPD & Medium \\
\hline & CUL4A & Low & & DSE & Medium \\
\hline & GMPR2 & Medium & & KIF1B & High \\
\hline & HNRNPC & High & & LAMTOR3 & Medium \\
\hline & HSPD1 & Medium & & OCIAD1 & Medium \\
\hline & ITGB1 & High & & PHF20L1 & Low \\
\hline & LAMP2 & High & & RAB24 & Low \\
\hline & LYST & Low & & RAB2A & High \\
\hline & NFE2L2 & High & & RBM25 & High \\
\hline & PCNP & High & & SLC44A2 & Medium \\
\hline & PFDN5 & High & & SORL 1 & High \\
\hline & PPM1B & Medium & & SUPT4H1 & Low \\
\hline & RBM39 & Low & & TNRC6A & High \\
\hline & RBMX & High & & VMP1 & Medium \\
\hline & RHEB & Low & & WIPF1 & Low \\
\hline & SEPT2 & Medium & & WLS & Low \\
\hline
\end{tabular}

Table 1: Classification of the 50 Root 66 genes according to gene function as outlined by Diaz-Beltran et al. (2016). Placental presence and detection level obtained by cross-referencing the Human Protein Atlas and Gene Cards websites.

\section{Conclusion}

Efforts have been made to diagnose ASD as early as possible [104], specifically because the burden of disease is extraordinary. In a cost-of-illness analysis, ASD was projected to account for up to $3.6 \%$ of GDP in 2025, exceeding the burden of stroke and hypertension $[105,106]$. Many research modalities have been explored to address this clinical challenge without much avail. Placental contributions to neurobehavioral developmental disorders have largely been neglected until recently. The placenta is a neuromodulator influencing brain morphology, regulating the environment for proper brain development and function, impacts fetal stress response and maternal immune activation. It is part of the HPG and HPA axes by way of its hormonal secretions and its dysfunction has been associated with clinically relevant neuropathological outcomes. Using iPSC technology can advance the placental origin of autism theory and provide new diagnostic and therapeutic markers for treatment. Re-conceptualizing ASD research involves the understanding that placental abnormality is a feature of ASD and that using of iPSC technology can examine the exact genetic, biochemical, and environmental factors that cause ASD development.

\section{Acknowledgement}

This research is supported by NICHD 5R21HD081682, and Robert Wood Johnson Foundation Grant \#67038 for their support of Child Health Institute of New Jersey.

\section{References}

1. Jauniaux E, Poston L, Burton GJ (2006) Placental-related diseases of pregnancy: involvement of oxidative stress and implications in human evolution. Hum Reprod Update 12: 747-755. [PubMed]
2. Rees S, Inder T (2005) Fetal and neonatal origins of altered brain development. Early Hum Dev 81: 753-761. [PubMed]

3. Sandman CA, Davis EP, Buss C, Glynn LM (2011) Prenatal Programming of Human Neurological Function. Int J Pept. 2011:837596. [PubMed]

4. Whitehouse AJO, Hickey M, Stanley FJ, Newnham JP, Pennell CE (2011) Brief report: a preliminary study of fetal head circumference growth in autism spectrum disorder. J Autism Dev Disord 41: 122-129. [PubMed]

5. Hobbs K, Kennedy A, DuBray M, Bigler ED, Petersen PB, et al. (2007) A retrospective fetal ultrasound study of brain size in autism. Biol Psychiatry 62: 1048-1055. [PubMed]

6. Nelson KB, Grether JK, Croen LA, Dambrosia JM, Dickens BF, et al. (2001) Neuropeptides and neurotrophins in neonatal blood of children with autism or mental retardation. Ann Neurol. 49: 597-606.

7. Casanova MF, van Kooten I, Switala AE, van England $H$, Heinsen $H$, et al (2006) Minicolumnar width abnormalities in autism. Acta Neuropathol 112: 287 303. [PubMed]

8. Bauman ML, Kemper TL (1994) Neuroanatomic observations of the brain in autism. Int J Dev Neurosci 23: 183-187. [PubMed]

9. Bauman ML, Kemper TL (2002) Neuropathology of infantile autism. Mol Psychiatry. 7: S12-13. [PubMed]

10. Eberhard S, Dittrich M, Bock J, Nanda I, Muller T, et al. (2016) CpG sites with continuously increasing or decreasing methylation from early to late human fetal brain development. Gene 592: 110-118. [PubMed]

11. Takahashi K, Yamanaka S (2006) Induction of pluripotent stem cells from mouse embryonic and adult fibroblast cultures by defined factors. Cell 126 663-676. [PubMed]

12. Xu RH, Chen X, Li DS, Li R, Addicks GC, et al. (2002) BMP4 initiates human embryonic stem cell differentiation to trophoblast. Nat Biotechnol. 20: 1261 1264. [PubMed]

13. Ben-Reuven L, Reiner O (2016) Modeling the autistic cell: iPSCs recapitulate developmental principles of syndromic and nonsyndromic ASD. Dev Growth Differ. 58: 481-491. [PubMed] 
Citation: Jasani S, Tartaglia G, Yeung PL, Lu CW (2018) A Review of the Placenta and Trophoblast Induced Pluripotent Stem Cells in Autism Spectrum Disorder Research. J Stem Cell Res Ther 8: 413. doi: 10.4172/2157-7633.1000413

14. Ji L, Brkic J, Liu M, Fu G, Peng C, et al. (2013). Placental trophoblast cell differentiation: physiological regulation and pathological relevance to preeclampsia. Mol Aspects Med 34: 981-1023. [PubMed]

15. Lei ZM, Rao CV (2001) Neural actions of luteinizing hormone and human chorionic gonadotropin. Seminars in reproductive medicine 19: 103-109. [PubMed]

16. Cunningham L, Bloom S, Hauth J, Rouse D, Spong C (2010) Williams Obstetrics. New York, New York: McGraw-Hill.

17. Gallego MJ, Porayette P, Kaltcheva MM, Bowen RL, Meethal SV, et al. (2010) The pregnancy hormones human chorionic gonadotropin and progesterone induce human embryonic stem cell proliferation and differentiation into neuroectodermal rosettes. Stem Cell Res Ther 1: 28. [PubMed]

18. Petraglia F (1997) Inhibin, activin and follistatin in the human placenta--a new family of regulatory proteins. Placenta 18: 3-8.

19. Petraglia F, Santuz M, Florio P, Simoncini T, Luisi S, et al. (1998) Paracrine regulation of human placenta: control of hormonogenesis. J Reprod Immunol 39: $221-233$

20. Wegiel J, Kuchna I, Nowicki K, Imaki H, Wegiel J, et al. (2010) The neuropathology of autism: defects of neurogenesis and neuronal migration, and dysplastic changes. Acta Neuropathol 119: 755-770. [PubMed]

21. Nugent BM, Bale TL (2015) The omniscient placenta: Metabolic and epigenetic regulation of fetal programming. Front Neuroendocrinolo 39: 28-37. [PubMed]

22. Barry G, Briggs JA, Hwang DW, Nayler SP, Fortuna PRJ, et al. (2017) The long non-coding RNA NEAT1 is responsive to neuronal activity and is associated with hyper excitability states. Sci Rep 7: 40127. [PubMed]

23. Keverne EB (2013) Importance of the matriline for genomic imprinting, brain development and behaviour. Philos Trans R Soc Lond B Biol Sci 368 : 20110327. [PubMed]

24. Volpe JJ (1981) Neurology of the newborn. Major Probl Clin Pediatr. 22: 1-648.

25. Rosenfeld CS (2015) Microbiome Disturbances and Autism Spectrum Disorders. Drug metabolism and disposition: the biological fate of chemicals 43: 1557-1571. [PubMed]

26. Schendel DE, Gronborg TK, Parner ET (2014) The genetic and environmental contributions to autism: looking beyond twins. Jama 311: 1738-1739. [PubMed]

27. Dimasuay KG, Boeuf P, Powell TL, Jansson $T$ (2016) Placental Responses to Changes in the Maternal Environment Determine Fetal Growth. Frontiers in Physiology 7: 12. [PubMed]

28. Sandovici I, Hoelle K, Angiolini E, Constância M (2012) Placental adaptations to the maternal-fetal environment: implications for fetal growth and developmental programming. Reprod Biomed Online 25: 68-89. [PubMed]

29. Kantola M, Purkunen R, Kroger P, Tooming A, Juravskaja J, et al. (2000) Accumulation of cadmium, zinc, and copper in maternal blood and developmental placental tissue: differences between Finland, Estonia, and St. Petersburg. Environ Res 83: 54-66. [PubMed]

30. Craciun EC, Bjorklund G, Tinkov AA, Urbina MA, Skalny AV, et al. (2016) Evaluation of whole blood zinc and copper levels in children with autism spectrum disorder. Metabolic brain disease 31: 887-890. [PubMed]

31. Tian X, Anthony K, Neuberger T, Diaz FJ (2014) Preconception Zinc Deficiency Disrupts Postimplantation Fetal and Placental Development in Mice. Biology of Reproduction 90: 83. [PubMed]

32. Owens S, Gulati R, Fulford AJ, Sosseh F, Denison FC, et al. (2015) Periconceptional multiple-micronutrient supplementation and placental function in rural Gambian women: a double-blind, randomized, placebo-controlled trial. Am J Clin Nutr 102: 1450-1459. [PubMed]

33. Van Weyenbergh J, Santana G, D'Oliveira A, Santos AF, Costa CH, et al. (2004) Zinc/copper imbalance reflects immune dysfunction in human leishmaniasis: an ex vivo and in vitro study. BMC Infect Dis 4: 50. [PubMed]

34. Lee SH, Lancey R, Montaser A, Madani N, Linder MC (1993) Ceruloplasmin and copper transport during the latter part of gestation in the rat. Proceedings of the Society for Experimental Biology and Medicine Society for Experimental Biology and Medicine 203: 428-439.

35. Guller S, Buhimschi CS, Ma YY, Huang STJ, Yang L, et al. (2008) Placental expression of ceruloplasmin in pregnancies complicated by severe preeclampsia. Lab Invest 88: 1057-1067. [PubMed]
36. Chauhan A, Chauhan V, Brown WT, Cohen I (2004) Oxidative stress in autism: increased lipid peroxidation and reduced serum levels of ceruloplasmin and transferrin--the antioxidant proteins. Life sciences 75: 2539-2549. [PubMed]

37. Germain ND, Chen PF, Plocik AM, Glatt-Deeley H, Brown J, Fink, et al. (2014) Gene expression analysis of human induced pluripotent stem cell-derived neurons carrying copy number variants of chromosome 15q11-q13.1. Mol Autism 5: 44. [PubMed]

38. Gore AC, Martien KM, Gagnidze K, Pfaff D (2014) Implications of Prenatal Steroid Perturbations for Neurodevelopment, Behavior, and Autism. Endocrine Reviews 35: 961-991. [PubMed]

39. Pfaff DW, Rapin I, Goldman S (2011) Male predominance in autism neuroendocrine influences on arousal and social anxiety. Autism Res 4: 163176. [PubMed]

40. Cvitic S, Longtine MS, Hackl H, Wagner K, Nelson MD, et al. (2013) The Human Placental Sexome Differs between Trophoblast Epithelium and Villous Vessel Endothelium. PLoS ONE 8: e79233. [PubMed]

41. Gabory A, Ferry L, Fajardy I, Jouneau L, et al. (2012) Maternal Diets Trigger Sex-Specific Divergent Trajectories of Gene Expression and Epigenetic Systems in Mouse Placenta. PLoS ONE 7: e47986. [PubMed]

42. Gabory A, Roseboom TJ, Moore T, Moore LG, Junien C (2013) Placental contribution to the origins of sexual dimorphism in health and diseases: sex chromosomes and epigenetics. Biol Sex Differ 4: 5. [PubMed]

43. King V, Hibbert N, Seckl JR, Norman JE, Drake AJ (2013) The effects of an obesogenic diet during pregnancy on fetal growth and placental gene expression are gestation dependent. Placenta 34: 1087-1090. [PubMed]

44. Kim DW, Young SL, Grattan DR, Jasoni CL (2014) Obesity during pregnancy disrupts placental morphology, cell proliferation, and inflammation in a sexspecific manner across gestation in the mouse. Biol Reprod 90: 130. [PubMed]

45. An JY, Claudianos C (2016) Genetic heterogeneity in autism: From single gene to a pathway perspective. Neurosci Biobehav Rev 68: 442-453. [PubMed]

46. Chen JA, Penagarikano O, Belgard TG, Swarup V, Geschwind DH (2015) The emerging picture of autism spectrum disorder: genetics and pathology. Annual review of pathology 10: 111-144. [PubMed]

47. Parikshak NN, Gandal MJ, Geschwind DH (2015) Systems biology and gene networks in neurodevelopmental and neurodegenerative disorders. Nat Rev Genet 16: 441-458. [PubMed]

48. Wall DP, Esteban FJ, Deluca TF, Huyck M, Monaghan T, et al. (2009) Comparative analysis of neurological disorders focuses genome-wide search for autism genes. Genomics 93: 120-129. [PubMed]

49. Diaz-Beltran L, Esteban FJ, Wall DP (2016) A common molecular signature in ASD gene expression: following Root 66 to autism. Transl Psychiatry 6: e705. [PubMed]

50. Langridge AT, Glasson EJ, Nassar N, Jacoby P, Pennell C, et al. (2013) Maternal conditions and perinatal characteristics associated with autism spectrum disorder and intellectual disability. PloS one 8: e50963. [PubMed]

51. Thornburg K, O'Tierney P, Louey S (2010) The placenta is a programming agent for cardiovascular disease. Placenta 31: S54-S59. [PubMed]

52. Ray JG, Vermeulen MJ, Schull MJ, Redelmeier DA (2005) Cardiovascular health after maternal placental syndromes (CHAMPS): population-based retrospective cohort study. Lancet 366: 1797-1803. [PubMed]

53. Burton GJ, Fowden AL, Thornburg KL (2016) Placental Origins of Chronic Disease. Physiol Rev 96: 1509-1565. [PubMed]

54. Barker D, Osmond C, Grant S, Thornburg KL, Cooper C, et al. (2013) Maternal Cotyledons At Birth Predict Blood Pressure In Childhood. Placenta 34: 672675. [Pubmed]

55. Barker DJ, Bull AR, Osmond C, Simmonds SJ (1990) Fetal and placental size and risk of hypertension in adult life. BMJ: Brit Med J 301: 259-262. [Pubmed]

56. Barker DJ, Hales CN, Fall CH, Osmond C, Phipps K, et al. (1993) Type 2 (non-insulindependent) diabetes mellitus, hypertension and hyperlipidaemia (syndrome $\mathrm{X}$ ): relation to reduced fetal growth. Diabetologia 36: 62-67. [Pubmed]

57. Barker DJ, Osmond C, Forsen TJ, Thornburg KL, Kajantie E, et al. (2013) Foetal and childhood growth and asthma in adult life. Acta Paediatr 102: 732738. [Pubmed] 
Citation: Jasani S, Tartaglia G, Yeung PL, Lu CW (2018) A Review of the Placenta and Trophoblast Induced Pluripotent Stem Cells in Autism Spectrum Disorder Research. J Stem Cell Res Ther 8: 413. doi: 10.4172/2157-7633.1000413

58. Barker DJP, Thornburg KL, Osmond C, Kajantie E, Eriksson (2010) The surface area of the placenta and hypertension in the offspring in later life. The Int $\mathrm{J}$ Develop Bio 54: 525-530. [Pubmed]

59. Eriksson JG, Kajantie E, Thornburg KL, Osmond C, Barker DJP (2011) Mother's body size and placental size predict coronary heart disease in men. Eur Heart J 32: 2297-2303. [Pubmed]

60. Van Abeelen AF, de Rooij SR, Osmond C, Painter RC, Veenendaal MV, et al. (2011) The sex-specific effects of famine on the association between placental size and later hypertension. Placenta 32: 694-698. [Pubmed]

61. Duthie L, Reynolds RM (2013) Changes in the maternal hypothalamic-pituitaryadrenal axis in pregnancy and postpartum: influences on maternal and fetal outcomes. Neuro Endo 98: 106-115. [Pubmed]

62. Cohen E, Baerts W, van Bel F (2015) Brain-Sparing in Intrauterine Growth Restriction: Considerations for the Neonatologist. Neonat 108: 269-276. [Pubmed]

63. Mysorekar IU, Diamond MS (2016) Modeling Zika Virus Infection in Pregnancy New Eng J Med 375: 481-484. [Pubmed]

64. Sun K, Adamson SL, Yang K, Challis JR (1999) Interconversion of cortisol and cortisone by 11 beta-hydroxysteroid dehydrogenases type 1 and 2 in the perfused human placenta. Placenta 20: 13-29. [Pubmed]

65. Davis EP, Pfaff D (2014) Sexually Dimorphic Responses to Early Adversity: Implications for Affective Problems and Autism Spectrum Disorder. Psych Neuro Endo 11-25. [Pubmed]

66. Bonnin A, Goeden N, Chen K, Wilson ML, King J, et al. (2011) A transient placental source of serotonin for the fetal forebrain. Nature 472: 347-350. [Pubmed]

67. de Weerth C, Buitelaar JK (2005) Physiological stress reactivity in human pregnancy-a review. Neuro Sci Bio Behav Rev 29: 295-312. [Pubmed]

68. Sandman CA, Wadhwa PD, Chicz-DeMet A, Dunkel-Schetter C, Porto M (1997) Maternal stress, HPA activity and fetal/infant outcome. Annals of the New York Academy of Sciences 814: 266-275. [Pubmed]

69. Tollenaar MS, Beijers R, Jansen J, Riksen-Walraven JM, et al. (2011) Maternal prenatal stress and cortisol reactivity to stressors in human infants. Stress 14 : 53-65. [Pubmed]

70. Mparmpakas D, Zachariades E, Sotiriadis G, Goumenou A, Harvey AJ, et al. (2014) Differential Expression of Placental Glucocorticoid Receptors and Growth Arrest-Specific Transcript 5 in Term and Preterm Pregnancies: Evidence for Involvement of Maternal Stress. Obst Gyne Int : 239278. [Pubmed]

71. Karteris E, Grammatopoulos D, Dai Y, Olah KB, Ghobara TB, et al. (1998) The human placenta and fetal membranes express the corticotropin-releasing hormone receptor 1alpha ( $\mathrm{CRH}-1$ alpha) and the $\mathrm{CRH}-\mathrm{C}$ variant receptor. The $\mathrm{J}$ Clin Endo Metab 83: 1376-1379. [Pubmed]

72. Bradley RG, Binder EB, Epstein MP, Tang Y, Nair HP, et al. (2008) Influence of Child Abuse on Adult Depression: Moderation by the Corticotropin-Releasing Hormone Receptor Gene. Arch Gen Psyc 65: 190-200. [Pubmed]

73. Knickmeyer R, Baron-Cohen S, Fane BA, Wheelwright S, Mathews GA, et al. (2006) Androgens and autistic traits: A study of individuals with congenital adrenal hyperplasia. Hormones and behavior 50: 148-153. [Pubmed]

74. Ng P (2000) The fetal and neonatal hypothalamic-pituitary-adrenal axis. Archives of Disease in Childhood. Fetal and Neonatal Edition 82: F250-F254. [Pubmed]

75. Hirst JJ, Kellehe MA, Walker DW, Palliser HK (2014) Neuroactive steroids in pregnancy: key regulatory and protective roles in the foetal brain. J Steroid Biochem Mol Bio 139: 144-153. [Pubmed]

76. Broad KD, Keverne EB (2011) Placental protection of the fetal brain during short-term food deprivation. Proceedings of the National Academy of Sciences of the United States of America 108: 15237-15241. [Pubmed]

77. Roseboom T, de Rooij S, and Painter R (2006) The Dutch famine and its longterm consequences for adult health. Early human development 82: 485-491. [Pubmed]

78. Gardner DS, Jackson AA, Langley-Evans SC (1997) Maintenance of maternal diet-induced hypertension in the rat is dependent on glucocorticoids. Hypertension 30: 1525-1530. [Pubmed]

79. Langley-Evans SC, Phillips GJ, Benediktsson R, Gardner DS, Edwards CR, et al. (1996) Protein intake in pregnancy, placental glucocorticoid metabolism and the programming of hypertension in the rat. Placenta 17: 169-172. [Pubmed]

80. Fernandez-Twinn DS, Ozanne SE (2010) Early life nutrition and metabolic programming. Annals of the New York Academy of Sciences 1212: 78-96. [Pubmed]

81. Baibazarova E, van de Beek C, Cohen-Kettenis PT, Buitelaar J, Shelton KH et al. (2013). Influence of prenatal maternal stress, maternal plasma cortiso and cortisol in the amniotic fluid on birth outcomes and child temperament at 3 months. Psych Neuro Endo 38: 907-915. [Pubmed]

82. McTernan CL, Draper N, Nicholson H, Chalder SM, Driver P, et al. (2001) Reduced placental 11beta-hydroxysteroid dehydrogenase type 2 mRNA levels in human pregnancies complicated by intrauterine growth restriction: an analysis of possible mechanisms. J Clin Endo Metab 86: 4979-4983. [Pubmed]

83. Bergman K, Glover V, Sarkar P, Abbott D, O'Connor TG (2010) In utero cortiso and testosterone exposure and fear reactivity in infancy. Hormones and Behavior 57: 306-312. [Pubmed]

84. Buss C, Davis EP, Shahbaba B, Pruessner JC, Head K, et al. (2012) Maternal cortisol over the course of pregnancy and subsequent child amygdala and hippocampus volumes and affective problems. Proceedings of the National Academy of Sciences of the United States of America 109: E1312-E1319. [Pubmed]

85. Huizink AC, Robles de Medina PG, Mulder EJ, Visser GH, Buitelaar JK (2003) Stress during pregnancy is associated with developmental outcome in infancy. Child Psy Psych Allied Disc 44: 810-818. [Pubmed]

86. Tsukada T, Simamura E, Shimada H, Arai T, Higashi N, et al. (2015) The Suppression of Maternal-Fetal Leukemia Inhibitory Factor Signal Relay Pathway by Maternal Immune Activation Impairs Brain Development in Mice. PLoS ONE 10: e0129011. [Pubmed]

87. Meyer U, Nyffeler M, Engler A, Urwyler A, Schedlowski M, et al. (2006) The time of prenatal immune challenge determines the specificity of inflammationmediated brain and behavioral pathology. J Neurosci 26: 4752-4762. [Pubmed]

88. Hsiao EY, Patterson PH (2011) Activation of the Maternal Immune System Induces Endocrine Changes in the Placenta via IL-6. Brain Behavior and Immunity 25: 604-615. [Pubmed]

89. Girard S, Tremblay L, Lepage M, Sebire G (2010) IL-1 receptor antagonist protects against placental and neurodevelopmental defects induced by maternal inflammation. J Immuno 184: 3997-4005. [Pubmed]

90. Garay PA, Hsiao EY, Patterson PH, McAllister AK (2013) Maternal immune activation causes age- and region-specific changes in brain cytokines in offspring throughout development. Brain, Behavior, and Immunity 31: 54-68. [Pubmed]

91. Smith SE, Li J, Garbett K, Mirnics K, Patterson PH (2007) Maternal immune activation alters fetal brain development through interleukin- 6 . The Journal of neuroscience: the official journal of the Society for Neuroscience 27: 10695 10702. [Pubmed]

92. Enstrom AM, Lit L, Onore CE, Gregg JP, Hansen R, et al. (2009) Altered Gene Expression and Function of Peripheral Blood Natural Killer Cells in Children with Autism. Brain Behavior and Immunity 23: 124-133. [Pubmed]

93. Chow ML, Pramparo T, Winn ME, Barnes CC, Li HR, et al. (2012) AgeDependent Brain Gene Expression and Copy Number Anomalies in Autism Suggest Distinct Pathological Processes at Young Versus Mature Ages. PLoS Genetics 8: e1002592. [Pubmed]

94. Glatt SJ, Tsuang MT, Winn M, Chandler SD, Collins M, et al. (2012) BloodBased Gene Expression Signatures of Autistic Infants and Toddlers: RH: BloodBased Autism Biomarkers. American Academy of Child and Adoles Psych 51: 934-44. [Pubmed]

95. Loke YJ, Hannan AJ, Craig JM (2015) The Role of Epigenetic Change in Autism Spectrum Disorders. Frontiers in Neuro 6: 107. [Pubmed]

96. Deshpande A, Yadav S, Dao DQ, Wu ZY, Hokanson KC, et al. (2017) Cellular Phenotypes in Human iPSC-Derived Neurons from a Genetic Model of Autism Spectrum Disorder. Cell Reports 21: 2678-2687. [Pubmed]

97. Walker CK, Anderson KW, Milano KM, Ye S, Tancredi DJ, et al. (2013) Trophoblast Inclusions Are Significantly Increased in the Placentas of Children in Families at Risk for Autism. Bio Psych 74: 204-211. [Pubmed]

98. Anderson GM, Jacobs-Stannard A, Chawarska K, Volkmar FR, Kliman H 
Citation: Jasani S, Tartaglia G, Yeung PL, Lu CW (2018) A Review of the Placenta and Trophoblast Induced Pluripotent Stem Cells in Autism Spectrum Disorder Research. J Stem Cell Res Ther 8: 413. doi: 10.4172/2157-7633.1000413

Page 9 of 11

(2007) Placental trophoblast inclusions in autism spectrum disorder. Bio Psych. 61: 487-491. [Pubmed]

99. Russo FB, Cugola FR, Fernandes IR, Pignatari GC, Beltrão-Braga, et al (2015) Induced pluripotent stem cells for modeling neurological disorders. World J Transp. 5: 209-221. [Pubmed]

100. Acab A, Muotri AR (2015) The Use of Induced Pluripotent Stem Cell Technology to Advance Autism Research and Treatment. Neurotherapeutics 12: 534-545. [Pubmed]

101. Russo FB, Freitas BC, Pignatari GC, Fernandes IR, Sebat J, et al. (2017) Modeling the Interplay Between Neurons and Astrocytes in Autism Using Human Induced Pluripotent Stem Cells. Bio Psych. [Pubmed]

102. Yuan L, Tang X, Zhang B, Ding G (2015) Cell Pluripotency Levels Associated with Imprinted Genes in Human. Computational and Mathematical Methods in Medicine 2015: 471076. [Pubmed]
103. Hu BY, Weick JP, Yu J, Ma LX, Zhang XQ, et al. (2010) Neural differentiation of human induced pluripotent stem cells follows developmental principles but with variable potency. Proceedings of the National Academy of Sciences of the United States of America 107: 4335-4340. [Pubmed]

104. Bock C, Kiskinis E, Verstappen G, Gu H, Boulting G, et al. (2011) Reference Maps of Human ES and iPS Cell Variation Enable High-Throughput Characterization of Pluripotent Cell Lines. Cell 144: 439-452. [Pubmed]

105. Andescavage NN, DuPlessis A, Limperopoulos C (2015) Advanced MR Imaging of the Placenta: Exploring the in utero placenta-brain connection. Seminars in Perinatology 39: 113-123. [Pubmed]

106. Leigh JP, Du J (2015) Brief Report: Forecasting the Economic Burden of Autism in 2015 and 2025 in the United States. Aut Devlop Dis 45: 4135-4139. [Pubmed] 